\title{
PARALELISMO ENTRE DP E CP A PARTIR DAS NOMINALIZAÇÕES NA LÍNGUA TENETEHÁRA
}

\section{PARALLELISM BETWEEN DP AND CP BASED ON NOMINALIZATIONS IN TENETEHÁRA LANGUAGE}

\author{
Quesler Fagundes Camargos* \\ Ricardo Campos Castro ${ }^{* *}$
}

RESUMO: Neste artigo, pretendemos investigar as nominalizações na língua Tenetehára (família Tupí-Guaraní) a fim de demonstrar que o DP e o CP contêm os núcleos funcionais To e Aspo, os quais são responsáveis pela codificação do tempo e do aspecto das sentenças nominais e verbais. A partir das ideias essenciais da proposta de Chomsky $(2001,2002)$, nossa hipótese é que os morfemas de tempo que aparecem em DPs e em CPs podem ser tratados como uma instanciação morfológica do núcleo funcional To. Essa morfologia serve como evidência de que ocorre atribuição de Caso estrutural para os possuidores e para os argumentos internos, ambos dentro do DP e do CP, respectivamente.

PALAVRAS-CHAVE: Tempo. Atribuição de caso. Nominalização. Língua Tenetehára. Tupí-Guaraní.

\footnotetext{
* Universidade Federal de Minas Gerais (UFMG), Belo Horizonte, Minas Gerais, Brasil. Doutorando no Programa de Pós-Graduação em Estudos Linguísticos da Faculdade de Letras da UFMG. Mestre em Estudos Linguísticos da Faculdade de Letras da UFMG. E-mail: queslerc@yahoo.com.br.

** Universidade Federal de Minas Gerais (UFMG), Belo Horizonte, Minas Gerais, Brasil. Doutorando no Programa de Pós-Graduação em Estudos Linguísticos da Faculdade de Letras da UFMG. Mestre em Estudos Linguísticos da Faculdade de Letras da UFMG. E-mail: ricardorrico@uol. com.br.
} 
ABSTRACT: In this paper, we investigate the nominalization constructions in Tenetehára language (Tupí-Guaraní family) in order to demonstrate that both the DP and the CP contain the functional head To and Aspo which are responsible for encoding the tense and aspectual meaning of the sentences. Following the essential ideas of Chomsky's $(2000,2001)$ proposal, our hypothesis is that the temporal morphemes that appear in DPs and in TPs can be treated as a morphological instantiations of the functional head To. They also serve as a piece of evidence that there really occurs the structural Case assignment to possessors and to internal arguments both within the $\mathrm{CP}$ and within the DP.

KEYWORDS: Tense. Case assignment. Nominalization. Tenetehára language. Tupí-Guaraní. 


\section{PARALELISMO ENTRE DP E CP A PARTIR DAS NOMINALIZAÇÕES NA LÍNGUA TENETEHÁRA ${ }^{1}$}

\section{INTRODUÇÃO}

No âmbito da Teoria Gerativa, há um número pequeno de categorias gramaticais universais e primitivas, a saber: $\mathrm{N}$ (nomes), $\mathrm{V}$ (verbos), A (adjetivos) e P (preposições). De acordo com Chomsky (1965, 1970), os núcleos lexicais se identificam com as categorias lexicais que são definidas pela

1 Gostaríamos de registrar nossos agradecimentos a dois pareceristas anônimos da Revista da ANPOLL, cujas críticas contribuíram para o aperfeiçoamento deste artigo. Ao Prof. Fábio Bonfim Duarte, estendemos nossos mais sinceros agradecimentos por sua assistência. Agradecemos ainda as audiências do III Simpósio Internacional de Linguísticas Ameríndia da ALFAL (Rio de Janeiro, 2012), do III Encuentro de Lenguas Indígenas Americanas da ALFAL (Bariloche, Argentina, 2013), do VIII Congresso Internacional da ABRALIN (Natal, Rio Grande do Norte, 2013) e do Encontro do GTTG da ANPOLL (São Paulo, 2013), eventos em que esse trabalho foi parcialmente apresentado. Os erros e as inconsistências que persistem são de nossa inteira responsabilidade. Esta pesquisa conta com o apoio de uma bolsa de pesquisa, financiada pela FAPEMIG (projeto número 19901) e com o apoio da Pró-Reitoria de Pesquisa da Universidade Federal de Minas Gerais (PRPq/UFMG). Parte desta investigação foi desenvolvida durante trabalho a campo realizado na terra indígena de Araribóia (nas aldeias Lagoa Quieta e Barreirinha). Gostaríamos de agradecer o importante apoio do povo indígena Tenetehára que nos ajudou no levantamento dos dados linguísticos que compõem esta pesquisa, em especial aos índios Cíntia Guajajára, Pedro Guajajára e Raimundo Guajajára. 
combinação de dois traços distintivos e fundamentais, a saber: o nominal [+/-N] e o verbal [+/-V]. A combinação desses traços fornece as possibilidades apresentadas no Quadro 1.

QUADRO 1: Núcleos lexicais

\begin{tabular}{lll}
\hline & {$[+\mathrm{N}]$} & {$[-\mathrm{N}]$} \\
\hline$[-\mathrm{V}]$ & Nome & preposição \\
{$[+\mathrm{V}]$} & adjetivo & verbo \\
\hline
\end{tabular}

Cada uma das categorias definidas acima tem um conjunto de propriedades prototípicas, as quais são capazes de distinguir uma das outras. Apresentamos abaixo as principais características tradicionalmente atribuídas aos verbos e aos nomes, como aponta Alexiadou (2005).

QUADRO 2: Propriedades de nomes (N) e verbos (V)

\begin{tabular}{llll}
\hline \multicolumn{2}{l}{ Nomes } & \multicolumn{2}{l}{ Verbos } \\
\hline a. & são expressões referenciais & a. & denotam eventos \\
b. & não possuem argumentos & b. & possuem argumentos \\
c. & $\begin{array}{c}\text { são flexionados para núme- } \\
\text { ro, gênero, definitude e caso }\end{array}$ & c. & são flexionados para tempo, aspecto, \\
\hline
\end{tabular}

No entanto, alguns estudos acerca da arquitetura oracional e nominal têm mostrado um forte paralelismo entre a estrutura das sentenças e a estrutura dos nomes, como pode ser visto nos trabalhos de Abney (1987), Pollock (1989), Rizzi (1997, 2004), Marantz (1997), Vangsnes (1999), Cinque (1999, 2002), Zamparalli (2000), Belletti (2004) e Aboh (2004). Acompanhando os pressupostos presentes nesses trabalhos, proporemos, neste artigo, que as projeções de CP e de DP têm as seguintes estruturas geometricamente articuladas e paralelas, as quais foram adaptadas a partir de Hiraiwa (2005: 19): 


\section{Domínio de CP}

(1)

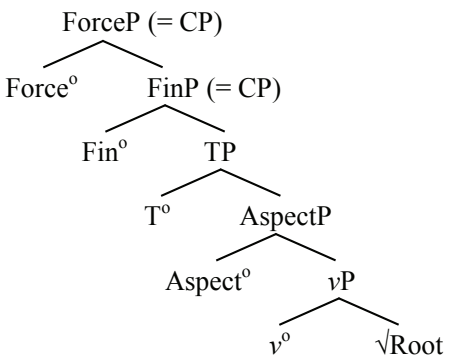

\section{Domínio de DP}

(2)

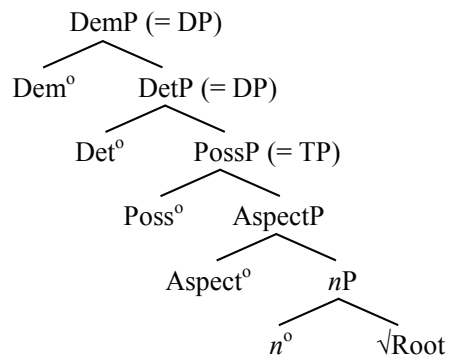

ForceP e FinP correspondem aos núcleos "Force" e "Fin(iteness)" da Teoria da Periferia Esquerda de $\operatorname{Rizzi}^{2}$ (1997, 2004). Paralelamente, as projeções DemP e DetP contêm os núcleos de determinantes demonstrativos e determinantes de definitude, respectivamente. A projeção de PossP no domínio do DP é análoga ao TP no domínio de CP. Estas projeções PossP e TP são responsáveis pela atribuição de Caso e pela concordância. Aspect ${ }^{\circ}$ é o núcleo que apresenta os aspectos verbais e nominais. Por fim, os elementos $v^{0}$ e $n^{03}$ são os núcleos que categorizam a raiz $\sqrt{ }$, nos termos de Marantz (1997). Na próxima seção, faremos uma breve apresentação de trabalhos que sustentam a hipótese de que as estruturas do DP e do CP são, de fato, paralelas.

2 Segundo Rizzi $(1997,2004)$, o domínio de C ${ }^{\circ}$ é decomposto em outros núcleos: cada função oracional de $\mathrm{C}^{\circ}$ é analisada como um núcleo distinto (Force ${ }^{\circ}$, Fin ${ }^{\circ}$, etc) e cada núcleo funcional, por sua vez, pode merge 'juntar' um especificador, no máximo, de modo que qualquer sintagma deslocado passa a dispor de um único especificador de um núcleo distinto. Dentre esses núcleos, destacamos: (i) ForceP tem a função de expressar se a sentença é declarativa, interrogativa, exclamativa, relativa ou adverbial (esse núcleo é obrigatório nas sentenças, mesmo quando não é fonologicamente instanciado) e (ii) FinP contém uma especificação de tempo (finito ou não finito) que concorda com o do domínio de IP (i.e. TP).

3 Este núcleo $v^{\circ}$, o qual pode ser visto logo acima da raiz $\sqrt{ }$ Root na estrutura em (1), não corresponde ao núcleo causativo $v^{0}$ proposto por Larson (1988) e adotado por Chomsky (1995). Na verdade, o rótulo $v^{0}$ será mantido neste trabalho nos termos de Marantz (1997), em que esse núcleo $v^{\circ}$ tem a propriedade funcional de categorizar verbos (i.e. por meio de afixação de morfemas derivacionais, por exemplo). A projeção nominal análoga ao núcleo de $v \mathrm{P}$ é a projeção de $n \mathrm{P}$, conforme a estrutura (2), cuja função é categorizar nomes. No finlandês, por exemplo, conforme Pylkkänen (2002: 94), um nome e um verbo podem ser identificados por meio de sufixos de morfema derivacional, a saber: $\{-e\}$ deriva nome e $\{-o\}$ deriva verbos. Assim, a raiz kats "olhar" nessa língua pode ser o nome kats-e "o olhar" ou o verbo kats-o "olhar". Para nos referir ao núcleo causativo $v^{\circ}$ de Larson (1988) e Chomsky (1995), utilizaremos o rótulo $v \mathrm{P}_{\text {CAUSE }}$, cujo núcleo é $v_{\text {CAUSE }}^{\text {o }}$. 


\section{EVIDÊNCIAS TRANSLINGUÍSTICAS DO PARALELISMO ENTRE $O$ DP E O CP}

Szabolcsi $(1983,1994)$ argumenta que o DP e o CP são análogos com base no princípio de que os determinantes são a contraparte dos complementizadores. A autora mostra que os núcleos $\mathrm{C}^{\circ}$ e $\mathrm{D}^{\circ}$ são subordinadores e a uniformidade de suas propriedades é responsável pelo estreito paralelismo entre CP e DP.

Em termos de Caso e concordância, por exemplo, algumas línguas usam a mesma marcação de Caso para agentes e possessivos. Szabolcsi (1983, 1994) mostra que o húngaro usa a marca de nominativo \{te\}, como em (3), e o yup'ik esquimó utiliza a marca de ergativo $\{-m\}$ (também chamado de Caso relativo), como em (4), a fim de assinalar os argumentos agentes e possuidores ${ }^{4}$.

\begin{tabular}{|c|c|c|}
\hline te & $v e-t t-e l$ & egy \\
\hline $\begin{array}{l}\text { 2SG.NOM } \\
\text { "Você cor }\end{array}$ & $\begin{array}{l}\text { comprar-PAST-2SG.ID } \\
\text { prou um chapéu" }\end{array}$ & ID \\
\hline
\end{tabular}

(3b)

$\begin{array}{lll}a & \boldsymbol{t} \boldsymbol{e} & k \text { kalap-ja-i-d } \\ \text { D } & \text { 2sG.NOM } & \text { chapéu-Poss-PL-2sG } \\ \text { "Seus chapéus" } & \end{array}$

$(4 a)$

angute- $m$

nera-a

neqa

homem-RELAT

comer-3sG.3sG

peixe

"O homem está comendo o peixe"

\footnotetext{
4 Abreviaturas utilizadas neste trabalho: 1: primeira pessoa; 2: segunda pessoa; 3: terceira pessoa; ABS: Caso absolutivo; ACC: Caso acusativo; APPL: morfema aplicativo; ASPECT: morfema aspectual; AUX: auxiliar; C: prefixo relacional de contiguidade; CAUS: morfema causativo; CORR: morfema correferencial; D: determinante; DESID: morfema desiderativo; ENF: morfema enfático; ERG: Caso ergativo; FUT: futuro; GEN: Caso genitivo; INTS: intensificador; NC: prefixo relacional de não contiguidade; NOM: Caso nominativo; NOML: morfema nominalizador; O: objeto; OBL: Caso oblíquo; PF: partícula final; PAST: passado; PAST.REC: passado recente; PERF: perfectivo; PL: plural; POSS: possessivo; PREP: preposição; REL: prefixo relacional; RELAT: Caso relativo; REP: reduplicação; S: sujeito; SG: singular; TRANS: morfema transitivizador.
} 
angute- $m$

homem-RELAT

"Os cachorros do homem" qimugta-i

cachorro-3PL.ABS.3SG.ERG

Conforme Lefebvre \& Muysken (1988), o quéchua de Cusco também apresenta um paralelismo nos padrões de Caso e concordância dentro de certas orações e de sintagmas nominais. Note que, nos exemplos abaixo, o morfema de Caso genitivo $\{-q\}$ é acionado para indicar o sujeito do verbo bitransitivo em (5a) e o possuidor do sintagma nominal em (5b). Mais especificamente, os argumentos de predicados verbais e nominais recebem a mesma marca morfológica.

$\begin{array}{llll}\text { runa-q } & \text { qulqui- } \varnothing & q u-s q a-n & \text { warmi-man } \\ \text { homem-GEN } & \text { dinheiro-ACC } & \text { dar-NOML-3 } & \text { mulher-para }\end{array}$

"A mulher para quem o homem deu o dinheiro"

$\begin{array}{llll}\text { Pidru- } \boldsymbol{q} & \text { ancha } & \text { hatun } & \text { wasi-n-man } \\ \text { Pedro-GEN } & \text { muito } & \text { grande } & \text { casa-3-para } \\ \text { "A casa muito grande de Pedro" } & & \end{array}$

Collins (2001), por sua vez, mostra que projeções verbais e nominais em thoan compartilham o mesmo morfema $\{k i$ - $\}$ para indicar pluralidade em eventos (quando se realiza junto a verbos), como em (6a), e em nomes, como em (6b).

jefo $\quad \boldsymbol{k i}$-tchi-tcu $\quad$-'a $\quad \odot^{\prime} u \quad k i \quad \| a " a-q a$

Jeff kí[PL.]-atirar-REP PERF antílope PREP seta-PL.

"Jeff atirou (várias vezes) no antílope com setas"

(6b)
○’u-qa kí

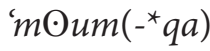
antílope-PL.
kí[PL.] cabeça-PL.
"As cabeças dos antílopes"

Adicionalmente, Lecarme (1996) e Wiltschko (2003) demonstram que a língua halkomelem salish apresenta evidências morfológicas da existência 
de tempo dentro do domínio nominal. Veja que os predicados verbais em (7a) e (8a) acionam os morfemas $\{-l h\}$ e $\{-c h a\}$ para indicar, respectivamente, o passado e o futuro. Paralelamente, os sintagmas nominais em (7b) e (8b) acionam os mesmos morfemas temporais que ocorrem nos verbos.

$(7 a)$

$\begin{array}{lll}\text { i-lh } & \text { tsel } & \text { lám } \\ \text { AUX-PAST } & \text { 2sG.S } & \text { ir }\end{array}$

"Eu estava indo"

(GALOWAY, 1993: 319)

(7b) te-l má:l-elh

D-1SG.POSs pai-PAST

"Meu falecido pai"

(BURTON, 1997: 67)

(8a) th 'í:qwe-th-omé-tsel-cha

socar-TRANS-2sG.O-2sG.S-FUT

"Eu vou dar um soco em você"

(GALOWAY, 1993: 317)

(8b) te-l swáqeth-cha
D-1SG.Poss marido-FuT
"Meu futuro marido"
(WILTSCHKO, 2003: 665)

Diante da discussão acima, o objetivo principal deste trabalho é o de encontrar uma resposta unificada à pergunta: qual é a origem da simetria entre o CP e o DP? A fim de responder a essa indagação, propomos atender aos seguintes tópicos: (i) examinar as propriedades dos morfemas de tempo, de aspecto e de voz causativa em Tenetehára ${ }^{5}$; (ii) abordar a questão do estatuto gramatical desses morfemas; e, por fim, (iii) questionar a categorização das

5 A língua Tenetehára é falada no nordeste do Brasil por dois povos indígenas: os Tembé e os Guajajára. De acordo com Rodrigues (1985), essa língua pertence ao Ramo IV da família linguística Tupí-Guaraní, do Tronco Tupí. 
classes de palavras e a estrutura configuracional dessas projeções. Para isso, esta investigação se fundamentará na hipótese de que há sim um paralelismo sintático entre sintagmas nominais e sintagmas verbais. Mais precisamente, defenderemos que CP e DP, em termos de projeções lexicais e funcionais no âmbito da sintaxe, não se diferem fundamentalmente em Tenetehára (apesar de eles se diferirem em algumas propriedades), o que contraria as teorias que buscam separar o CP e o DP em duas classes totalmente distintas.

\section{ANÁLISE DO TENETEHÁRA}

Nesta seção, apresentaremos evidências empíricas a favor do paralelismo entre o CP e o DP. Contudo, antes de mostrarmos as propriedades que essas projeções compartilham, considere o comportamento dos prefixos relacionais na língua Tenetehára.

\subsection{Prefixos relacionais}

Na tradição dos estudos descritivos de línguas indígenas brasileiras, são chamados de prefixos relacionais os morfemas que têm a função de codificar a adjacência de um argumento ao seu predicador. De acordo com Rodrigues (1990), estes prefixos relacionais marcam a contiguidade ou não contiguidade de um genitivo antes de um nome, um sujeito antes de um verbo descritivo, um objeto antes de um verbo transitivo e um nome antes de uma posposição. Esta propriedade flexional pode ser comprovada com os exemplos da língua Kamaiurá a seguir, retirados de Seki (2000: 56-57):

\section{Prefixos de contiguidade}

$\begin{array}{ll}\text { (9a) } \quad \text { je=r-up } & \\ & 1 \text { sg=c-pai } \\ & \text { "Meu pai" } \\ \text { (10a) } & \text { kunu'um-a } \quad r \text {-up } \\ & \text { menino-ARG } \quad \text { C-pai } \\ & \text { "Pai do menino" }\end{array}$

$$
\begin{aligned}
& j e=\emptyset-a k a \eta \\
& 1 \text { sg=c-cabeça } \\
& \text { "Minha cabeça" }
\end{aligned}
$$

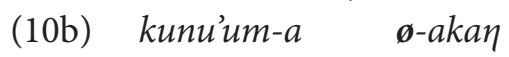

menino-ARg C-cabeça

"Cabeça do menino" 


\section{Prefixos de não contiguidade}

(11a)

$$
\begin{aligned}
& \boldsymbol{i} \text {-pyr-a amoete } \\
& \text { NC-casa-ARglonge } \\
& \text { "A casa dele é longe" }
\end{aligned}
$$

(11b)

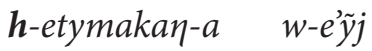
NC-perna-ARG 3-coçar

"Ele está coçando a perna dele ${ }_{\mathrm{k}}$ "

Note que, quando o possuidor está presente na construção, conforme (9) e (10), os núcleos acionam os prefixos $\{\varnothing-\infty r$ - $\}$ para indicar a adjacência do argumento nuclear (independente de o possuidor ser um pronome de primeira ou um sintagma nominal de terceira pessoa). Quando o possuidor é omitido, o núcleo passa a acionar os prefixos relacionais $\{i-\infty h$ - $\}$, cuja finalidade é a de indicar a não adjacência de seu argumento. $\mathrm{O}$ mesmo processo pode ser visto nas posposições na língua Tenetehára, conforme os exemplos abaixo, retirados de Camargos \& Duarte (2013:50):

\section{Prefixos de contiguidade}
(12a) ko
ø-pupe
mata C-dentro
(12b) ko r-ehe
mata c-em
"dentro da mata"
"na mata"

\section{Prefixos de não contiguidade}

(13a)

$\begin{array}{ll} & \text { i-pupe } \\ & \text { NC-dentro } \\ \text { "dentro dela (da mata)" }\end{array}$

(14a)

$$
\begin{aligned}
& { }^{* k o} \quad \boldsymbol{i} \text {-pupe } \\
& \text { mata } \quad \text { NC-dentro } \\
& \text { "dentro da mata" }
\end{aligned}
$$

(13b)

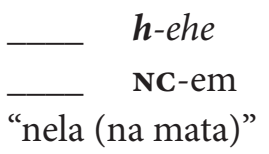

(14b)

$$
\begin{aligned}
& { }^{*} k o \quad \boldsymbol{h} \text {-ehe } \\
& \text { mata NC-em } \\
& \text { "na mata" }
\end{aligned}
$$

Observe que, caso o argumento da posposição coocorra com os prefixos relacionais de não adjacência, a sentença se torna agramatical, conforme os exemplos em (14). No entanto, Camargos \& Duarte (2013) mostram que esses prefixos têm um comportamento diferente quando se afixam a verbos descritivos, conforme os exemplos abaixo: 
(15a)

$h e=\emptyset-k a ̀ n$

1=1/2-forte

"Eu sou forte"

(16a) $n e=\varnothing-k a ̀ n$

2 sg=1/2-forte

"Você é forte" (15b) he=r-uryw

1=1/2-feliz

"Eu estou feliz"

(16b) ne $=\boldsymbol{r}-u r y w$

$2 \mathrm{sg}=\mathbf{1} / \mathbf{2}$-feliz

"Você está feliz"

$(17 b)$
awa
h-uryw
homem 3-feliz
"O homem está feliz"

Camargos \& Duarte (2013), acompanhando Lopes (2009), assumem que os prefixos relacionais, quando ocorrem em verbos descritivos, são o reflexo de concordância em pessoa do verbo com seu sujeito. Mais precisamente, quando o sujeito é de primeira ou segunda pessoa, o verbo aciona os prefixos $\{\varnothing-\infty r$ - $\}$ e, quando o sujeito é um DP de terceira pessoa, o verbo aciona os prefixos $\{i-\infty h$ - $\}$. A principal evidência dessa análise é o contraste entre (14) e (17). Mais especificamente, para os autores, a proposta é de que esses prefixos, na verdade, são a evidência do licenciamento de Caso abstrato ao seu argumento. A proposta de concordância ${ }^{6}$ pode ser vista resumidamente no Quadro 3, o qual foi retirado de Camargos \& Duarte (2013:51)

QUADRO 3: Estatuto dos prefixos relacionais nos verbos descritivos

\begin{tabular}{llll}
\hline TRAÇO & RAIZ INICIADA EM & RAIZ INICIADA EM & PESSOA \\
DISTINTIVO & CONSOANTE & VOGAL & GRAMATICAL \\
\hline [+PESSOA $]$ & $\emptyset-$ & $r-$ & $1^{\mathrm{a}}$ \\
& & & $2^{\mathrm{a}}$ \\
{$[-$ PESSOA $]$} & $i-$ & $h-$ & $3^{\mathrm{a}}$ \\
\hline
\end{tabular}

${ }_{6}$ Vale ressaltar que os prefixos $\{\mathrm{i}-\infty \mathrm{h}-\}$ ainda podem ocorrer com verbos intransitivos e transitivos, quando pertencem a orações encaixadas, a fim de estabelecer a concordância com o sujeito de intransitivo em (i) e com o objeto de transitivo em (ii).
(i) [...] awa h-eixe mehe homem 3-entrar quando "[...] quando o homem entrou"
(ii) [...] zapukaz i-zuka mehe galinha 3-matar quando "[...] quando ele(a) matou a galinha"


Na próxima subseção, demonstraremos que os prefixos relacionais, quando são engatilhados em construções nominalizadas em Tenetehára, exibem o mesmo comportamento visto nos verbos descritivos, a saber: exibem concordância em pessoa, conforme o Quadro 3, entre o predicador e seu argumento.

\subsection{Nominalizações}

De acordo com os trabalhos de Rodrigues (1953), Boudin (1978), Bendor-Samuel (1972), Harrison (1986), Duarte (1997, 2003, 2007), Carvalho (2001), Castro (2007), Silva (2010) e Camargos (2013), apresentamos, no Quadro 4, os morfemas nominalizadores na língua Tenetehára.

QUADRO 4: Nominalizadores na língua Tenetehára7

\begin{tabular}{|c|c|c|}
\hline & Noml & Descriçãao \\
\hline a. & $\{-h a w\}:$ & $\begin{array}{l}\text { nominaliza verbos inacusativos, inergativos e transitivos a fim } \\
\text { de indicar o evento ou o estado descrito pelo verbo; pode ain- } \\
\text { da codificar o lugar ou o instrumento relacionado à ação des- } \\
\text { crita pelo verbo. }\end{array}$ \\
\hline b. & $\left\{-m a^{\prime} e\right\}:$ & $\begin{array}{l}\text { nominaliza verbos inacusativos e inergativos a fim de se referir } \\
\text { ao argumento do predicado inicial. }\end{array}$ \\
\hline c. & $\{$-har $\}$ : & $\begin{array}{l}\text { nominaliza verbos transitivos com o objetivo de se referir ao } \\
\text { sujeito agente. }\end{array}$ \\
\hline d. & $\{e m i-\}:$ & $\begin{array}{l}\text { nominaliza verbos transitivos a fim de se referir ao objeto (o } \\
\text { prefixo relacional concorda o argumento do nome derivado). }\end{array}$ \\
\hline e. & $\{-p y r\}:$ & $\begin{array}{l}\text { nominaliza verbos transitivos a fim de se referir ao objeto (o } \\
\text { prefixo relacional não indica o argumento do nome derivado). }\end{array}$ \\
\hline
\end{tabular}

\subsubsection{Nominalizações com $\{$-haw}

O morfema $\{-h a w\}$ nominaliza predicados para introduzir, por exemplo, o significado de instrumento, conforme a sentença em (18). Note que esse exemplo ilustra a nominalização de um verbo transitivo.

7 Salientamos que as descrições apresentadas no Quadro 4 não compreendem todas as funções desses morfemas nominalizadores. Exibimos aqui as principais propriedades de cada um, as quais são suficientes para fundamentar os objetivos deste artigo. 
(18a)

$\begin{array}{llllll}\text { u-zàmi } & \text { kuzà } & \text { maniok } & \text { tàpixi } & \varnothing \text {-pupe } & \text { a'e } \\ \text { 3-espremer } & \text { mulher mandioca tipiti } & \text { C-com } & \text { 3SG }\end{array}$

"A mulher espremeu a mandioca com o tipiti"

(18b) o-mono kwarer $\left[_{\mathrm{DP}}\right.$ maniok i-zàmi-haw $]$ kuzà ø-pe a’e 3-dar menino mandioca 3-espremer-NomL mulher C-para $35 \mathrm{SG}$ "O menino deu o espremedor de mandioca para a mulher"

Note que, em (18a), o verbo zàmi "espremer" têm dois argumentos nucleares: o sujeito kuzà "mulher" e o argumento interno mani’k "mandioca”. Após a nominalização em (18b), o sintagma nominal maniok i-zàmi-haw "espremedor de mandioca" se refere à ferramenta que é utilizada para a execução da ação descrita pelo evento em (18a).

O nominalizador $\{-h a w\}$ se afixa a verbos a fim de determinar, além do instrumento, conforme o exemplo acima, o lugar, o evento ou a qualidade denotados pelo predicado inicial. Veja a seguir a nominalização de um verbo intransitivo.

\begin{tabular}{|c|c|c|}
\hline (19a) & $\begin{array}{l}\text { u-ker } \\
\text { 3-dormir }\end{array}$ & $\begin{array}{l}\text { kwarer } \\
\text { menino }\end{array}$ \\
\hline
\end{tabular}

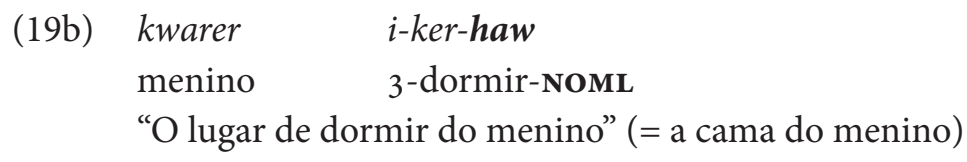

Conforme mostra o dado em (19a), o predicado intransitivo ker "dormir" seleciona o DP sujeito kwarer "menino". Por sua vez, em (19b), após o processo de nominalização, a predicação nominalizada $i$-ker-haw "o lugar de dormir” faz menção ao lugar relacionado ao evento descrito pelo verbo. Veja, a seguir, que o morfema $\{-h a w\}$ também nominaliza o verbo transitivo petek "bater" a fim de denotar o evento descrito pela base verbal. 
(20a)

$\begin{array}{llll}\text { u-petek } & \text { kwarer } & \text { zawar } & \text { a'e } \\ \text { 3-bater } & \text { menino } & \text { cachorro } & \text { 3SG } \\ \text { "O menino bateu no cachorro" } & & \end{array}$

(20b) zawar $\quad$ i-petek-haw-kwer
cachorro
"O evento (passado) de bater no cachorro"

Note que, em (20a), o predicado transitivo petek "bater" requer os argumentos nucleares kwarer "menino" e zawar "cachorro". Em (20b), por seu turno, depois do processo de nominalização, o sintagma nominal i-petek-haw-kwer "o evento (passado) de bater" demonstra que o morfema $\{-h a w\}$ denota uma nominalização que se refere ao evento descrito pelo verbo. Por fim, veja, a seguir, uma nominalização que indica o estado do verbo descritivo puràg "ser bonito".
(21a) i-puràg-ete
3-bonita-INTS
kuzà
a'e
"A mulher é bonita de verdade"
(21b) kuzà
i-puràg-ete-haw
mulher
3-bonita-INTS-NOML
"A beleza da mulher"

Observe que, em (21a), o predicado descritivo puràg "ser bonito" introduz o argumento kuzà "mulher". Em (21b), por sua vez, depois do processo de nominalização, a predicação nominalizada $i$-puràg-ete-haw "o estado de ser bonito (= a beleza)" demonstra que o morfema $\{$-haw $\}$ denota uma nominalização que se refere ao estado descrito pelo verbo descritivo inicial.

\subsubsection{Nominalizações com $\left\{-m a^{\prime} e\right\}$}

O morfema $\{-m a ’ e\}$ nominaliza predicados inacusativos e inergativos com o intuito de se referir ao argumento nuclear do predicado verbal inicial. A seguir ilustramos a nominalização do verbo inergativo zegar "cantar". 
(22a) u-zegar awa a'e

3-cantar homem 3SG

"O homem cantou"

\begin{tabular}{|c|c|c|c|}
\hline$(22 b)$ & $\begin{array}{l}\text { u-zán } \mathrm{I}_{\mathrm{DP}} \\
\text { 3-correr }\end{array}$ & $\begin{array}{l}\text { u-zegar-ma'e ] } \\
\text { 3-cantar-NoмL }\end{array}$ & a'e \\
\hline
\end{tabular}

Veja que, em (22a), figura o verbo inergativo zegar "cantar", ao passo que, em (22b), esse verbo é nominalizado, gerando o sintagma nominalizado $z e-$ gar-ma'e "o cantor", o qual se refere ao argumento agente da predicação inicial. A seguir, observe a nominalização do verbo inacusativo màno "morrer".

(23a) u-mànoawa a'e

3-morrer homem 3SG

"O homem morreu"

(23b) u-màno-ma'e-kwer

3-morrer-NOML-PAST

"Aquele que morreu" (= o defunto)

Na sentença em (23a), temos o verbo inacusativo màno "morrer" que seleciona o argumento nuclear awa "homem". No exemplo (23b), por sua vez, após a nominalização, o sintagma nominal u-màno-ma’e-kwer "aquele que morreu" indica o argumento afetado da predicação inicial não nominalizada.

Como pode ser visto em (22) e (23), as nominalizações com o morfema $\{-m a ’ e\}$ tem como resultado uma série de predicados nominalizados que obrigatoriamente fazem emergir os prefixos nominativos de terceira pessoa $\{u$ - $\}$. Mais detalhadamente, o prefixo $\{u-\}$ que ocorre nas formas nominalizadas é homófono ao prefixo de terceira pessoa que é engatilhado nos verbos para indicar a concordância com seu sujeito. Nas estruturas verbais, essa flexão de terceira pessoa concorda com o sujeito da predicação verbal, enquanto que nas nominalizações aparentemente não há uma concordância 
entre o predicador nominal e seu argumento. Uma alternativa ${ }^{8}$ seria propor, dentro da Teoria de Vinculação, conforme Chomsky $(1980,1986)$, que as nominalizações com o sufixo \{-ma’e\} em Tenetehára envolvem uma categoria vazia como argumento, mais detalhadamente um pro. Este elemento, visto que combina os traços [-anafórico] e [+pronominal], se comporta como um pronome. Assim, deve obedecer ao Princípio B ${ }^{9}$ da Teoria de Vinculação, sendo livre por meio de regência, conforme a representação a seguir:

$\left[\begin{array}{ll}\text { a-exak [ } \text { kuzà }_{\mathrm{k}} \quad\left[\text { pro }_{\mathrm{k}}\right. & \left.\left.\left.\boldsymbol{u}_{\mathrm{k}} \text {-zegar-ma'e-kwer }\right]\right]\right] \\ \text { 1sG-ver mulher } & \text { 3-cantar-NOML-PAST }\end{array}\right.$
"Eu vi a mulher que era cantora"

Veja que assumimos uma relação de correferência (= controle) entre o objeto kuzà "a mulher" da oração principal e o pro do predicado nominalizado, o que é assinalado pela coindexação acima. Além do mais, essa relação segue o Princípio B da Teoria de Vinculação, uma vez que essa categoria vazia está livre no seu domínio de vinculação e é controlada pelo DP kuzà "a mulher", o qual está fora de seu domínio.

\subsubsection{Nominalizações com $\{$-har $\}$}

Para que um verbo transitivo seja nominalizado, é imprescindível que o sufixo $\{$-har $\}$ se afixe a esse predicado. O resultado será um sintagma nominal com a função semântica de agente, conforme os exemplos abaixo.

$\begin{array}{lll}\text { u-pyhyk } & \text { awa } & \text { pira } \\ \text { 3-pegar } & \text { homem } & \text { peixe }\end{array}$

"O homem pegou um peixe" (= o homem pescou)

8 Agradecemos ao Prof. Dr. Fábio Bonfim Duarte por ter nos apontado essa solução teórica. Caso persista alguma incongruência na análise, é de nossa inteira responsabilidade.

9 Na Teoria da Vinculação, o Princípio B pode, assim, ser definidos:

Princípio B - um pronome precisa estar livre na sua categoria de regência. 


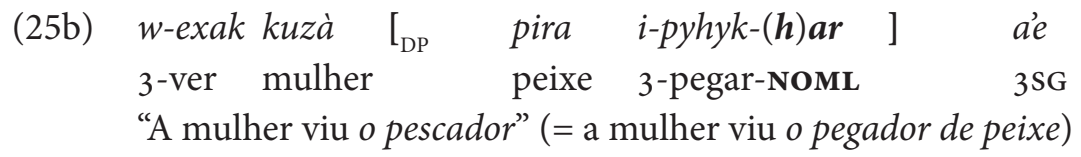

Pode-se notar que, em (25a), o verbo transitivo pyhyk "pegar" têm dois argumentos nucleares, a saber: os sintagmas nominais awa "homem" e pira "peixe", como seu sujeito e seu objeto, nessa ordem. Quando recebe o sufixo $\{-h a r\}$, conforme a sentença (25b), a nova predicação nominal pira $i$ -pyhyk-(h)ar "aquele que pega peixe" tem como referência o sujeito agente da predicação inicial.

\subsubsection{Nominalizações com \{emi-\}}

O verbo transitivo, quando recebe o nominalizador $\{e m i-\}$, torna-se um sintagma nominal, o qual, descritivamente, refere-se ao objeto do verbo transitivo inicial. O que chama a atenção é o fato de que o nome derivado recebe a série de prefixos relacionais, os quais são o resultado de concordância da estrutura nominalizada com o seu argumento nuclear. Este DP possuidor corresponde geralmente ao argumento externo da predicação verbal não nominalizada.

\begin{tabular}{|c|c|c|c|}
\hline & $\begin{array}{l}u-z u k a \\
\text { 3-matar }\end{array}$ & $\begin{array}{l}\text { zàwàruhu } \\
\text { onça }\end{array}$ & $\begin{array}{l}\text { tapi'ir } \\
\text { anta }\end{array}$ \\
\hline
\end{tabular}

"A onça matou a anta"

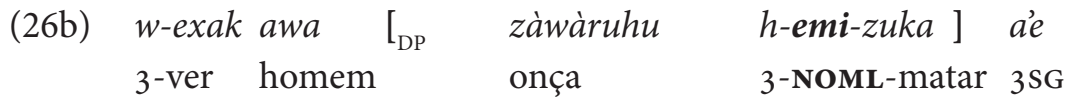

"O homem viu o matado da onça (i.e. a anta)"

Veja que, no exemplo (26a), o verbo $z u k a$ "matar" seleciona o sujeito zàwàruhu "onça" e o objeto tapi'ir "anta". Quando recebe o prefixo \{emi-\}, conforme (26b), o sintagma nominal gerado tem como referência o objeto do verbo transitivo inicial. Observe que o nominalizador $\{e m i-\}$ é o único 
morfema prefixal na língua em análise. Note mais dois exemplos a seguir, em que os predicados nominalizados recebem a série de prefixos relacionais a fim de se referir ao seu argumento interno, o qual geralmente se refere ao objeto da oração não nominalizada.

$\begin{array}{llll}\text { u-zapo-putar awa } & \text { tàpuz } & \text { a'e } & \text { nehe } \\ \text { 3-fazer-FUT homem } & \text { casa } & \text { 3SG } & \text { FUT } \\ \text { "O homem fará a casa" } & & & \end{array}$
awa
h-emi-apo-ràm
homem
3-NOML-fazer-FUT
"Aquilo que será feito pelo homem"

No exemplo em (27a), temos o predicado transitivo zapo "fazer", o qual seleciona o sujeito awa "homem" e o objeto tàpuz "casa”. Já, em (27b), o verbo recebe o prefixo nominalizador $\{e m i-\}$, gerando um nome que têm como referência o objeto do verbo transitivo inicial. Veja mais um exemplo abaixo que ilustra a nominalização de um verbo transitivo.

(28a) o-mokon awa muhàg a’e
3-engolir homem remédio 3SG
"O homem engoliu o remédio"

(28b) awa $\quad$ h-emi-mokon-kwer
homem $\quad$ 3-NOML-engolir-PAST
"Aquilo que foi engolido pelo homem"

Note que, no exemplo em (28a), há o predicado transitivo mokon "engolir", o qual seleciona o sujeito awa "homem" e o objeto muhàg "remédio". Já, em (28b), o verbo recebe o prefixo nominalizador $\{$ emi- $\}$, gerando um predicado nominal que têm como referência o objeto do verbo transitivo inicial, a saber: muhàg "remédio". 


\subsubsection{Nominalizações com $\{-p y r\}$}

O morfema $\{-p y r\}$, semelhante ao nominalizador $\{e m i-\}$, tem como função transformar verbos transitivos em sintagmas nominais que se refiram ao objeto dos predicados iniciais, conforme os exemplos abaixo:
(29a)
$\begin{array}{llll}\text { u-mu-ku'i } & k u z a ̀ ~ & k a p e & a ’ e \\ \text { 3-CAUs-moído } & \text { mulher } & \text { café } & \text { 3SG }\end{array}$
"A mulher moeu o cafe"

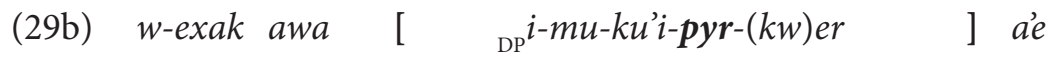 3-ver homem 3-CAUS-moído-NOML-PAST 3SG
"O homem viu aquilo que foi moído"

No exemplo (29a), temos o predicado transitivo $m u$-ku'i "moer" que seleciona o sujeito kuzà "mulher" e o objeto kape "café". Já em (29b), o predicado recebe o prefixo nominalizador $\{-p y r\}$ gerando um nome que tem como referência o objeto do verbo transitivo inicial. Diferente do nominalizador $\{e m i-\}$, a predicação nominalizada com o morfema $\{-p y r\}$ não introduz fonologicamente um argumento nuclear, apesar de acionar os prefixos relacionais $\{i-\infty h-\}$. Assim, uma solução teórica é assumirmos que as nominalizações com o sufixo $\{-p y r\}$, semelhante à nominalização com $\left\{-m a^{\prime}\right\}$, envolvem uma categoria vazia como argumento, provavelmente um pro. Esta categoria vazia, por ser um pronome, deve estar livre por meio de regência em seu domínio de vinculação, conforme a seguinte representação:

$$
\begin{aligned}
& \text { pro }_{\mathrm{k}} \quad \boldsymbol{i}_{\mathrm{k}}-m \boldsymbol{u}-k u^{\prime} i-p \boldsymbol{y} \boldsymbol{r}-(k w) e r \\
& \text { 3-CAUS-moído-NOML-PAST }
\end{aligned}
$$




\subsection{Paralelismo entre DP e CP em Tenetehára}

\subsubsection{Tempo no DP e no CP}

Independentemente do tempo da oração matriz, tanto o futuro quanto o passado podem ser marcados nos sintagmas nominais. Mais especificamente, não há uma relação biunívoca entre o tempo da predicação verbal e o tempo do DP. Veja os exemplos abaixo que demonstram essa afirmação.
teko paw
rakwez
w-enu
gente todos
PAST.REC 3-ouvir
$\Gamma_{\mathrm{DP}}$

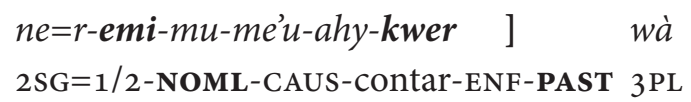
ri'i
$2 S G=1 / 2$-NOML-CAUS-Contar-ENF-PAST 3 PL PAST.
mundo ouviu seu juramento (i.e. aquilo que foi contado
"Todo mun você)" 3SG-ENF 3-CAUS-contar-FUT 3-NOML-fazer-PAST 3SG FUT "Ele ${ }_{\mathrm{k}}$ mesmo contará a feitura dele (i.e. aquilo feito por ele)"
(31b) a'e-ae u-mu-me'u-putar [ ${ }_{\mathrm{DP}}$ h-emi-apo-kwer ] a'e nehe

Veja que os predicados nominalizados acima, destacados entre colchetes, os quais acionam o morfema de passado $\{-k w e r\}$, podem se realizar em um predicado verbal que esteja no tempo passado, conforme (31a), ou no tempo futuro, como em (31b). Mais precisamente, note que, no exemplo (31a), a predicação principal está no tempo passado, visto que a oração contém as partículas temporais rakwez e ri $i$, as quais assinalam o tempo passado recente. Dessa forma, tanto o DP ne=r-emi-mu-me'u-ahy-kwer "seu juramento" quanto a predicação verbal estão no passado. No entanto, no exemplo (31b), a predicação verbal recebe as partículas putar e nehe de tempo futuro, enquanto que o DP h-emi-apo-kwer "a feitura dele" figura no tempo passado. Dessa maneira, neste último exemplo, há uma disjunção entre o tempo do DP e o tempo do CP.

Por seu turno, observe nos exemplos abaixo que as predicações nominalizadas que recebem o morfema de tempo futuro nominal $\{$-ràm\} também 
podem ocorrer em predicados verbais que atestam o tempo passado, conforme (32a), ou o tempo futuro, como em (32b).

\begin{tabular}{|c|c|}
\hline$r$ & rakwez \\
\hline
\end{tabular}

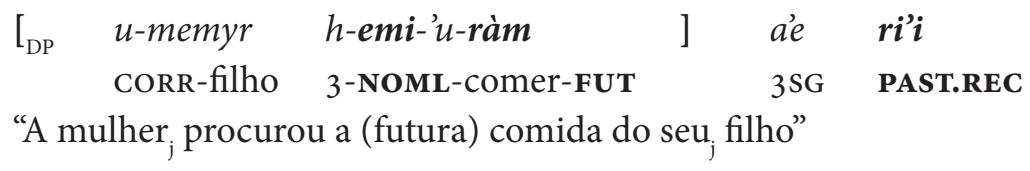

(32b) a'e mehe

a-mu-me'u-putar

então 1SG-CAUS-contar-FUT

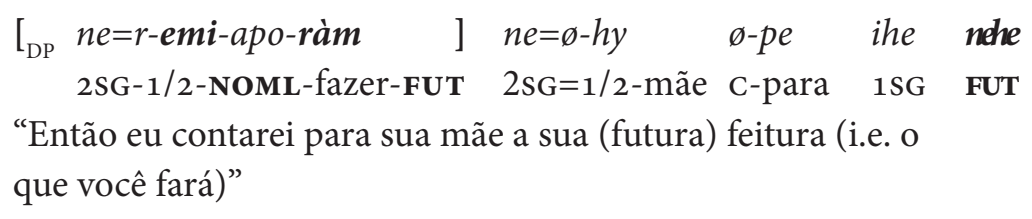

Mais detalhadamente, note que, em (32a), o DP u-memyr h-emi-'u-ràm "a comida (futura) do seu filho" contém o sufixo temporal \{-ràm\} para indicar que o evento nominalizado ainda não ocorreu, apesar de que a ação descrita pelo sintagma verbal está no tempo passado recente (i.e. os tempos em DP e em CP não coincidem). Por sua vez, observe que, em (32b), o DP ne=r-emi-apo-ràm "a sua (futura) feitura" contém o sufixo de tempo futuro $\{-r a ̀ m\}$ para indicar que a ação descrita pelo nome ainda ocorrerá. Neste último exemplo, os tempos tanto no DP quanto no CP se referem ao futuro.

Observe que os dados apresentados acima corroboram a hipótese de que o tempo nos DPs, pelo menos em Tenetehára, realiza-se independentemente do tempo codificado na oração matriz. Assim, essa disjunção temporal, vista em (31) e (32), sustenta a assunção inicial de que, assim como os verbos, os nomes também projetam uma categoria funcional capaz de codificar tempo. 
Veja ainda que os exemplos ${ }^{10}$ abaixo, retirados de Duarte (2005: 775), somam como argumento adicional a favor da hipótese de que os morfemas $\{$-ràm\} e $\{-k w e r\}$ de fato codificam tempo, uma vez que eles ocorrem, inclusive, em predicados verbais.

$\begin{array}{lllll}\text { teko } & \text { kon } & \text { u-zapo-ràm } & \text { typyj } & \text { nazewe } \\ \text { gente } & \text { quando } & 3 \text {-fazer-FuT } & \text { casa } & \text { assim }\end{array}$

"Quando a gente fará casa assim"

$\begin{array}{lll}\text { u-pinaityk-ràm } & \text { teko } & \text { o-ho } \\ \text { 3-pescar-FUT } & \text { gente } & 3 \text {-ir } \\ \text { "A gente pescará" } & & \end{array}$

$\begin{array}{llll}\text { a-ro- }(\boldsymbol{k}) \text { wer } & k a \text { 'a } & \text { r-upi } & \text { pihawy } \\ \text { 1sG-esperar-PAST } & \text { mato } & \text { C-em } & \text { noite } \\ \text { "Eu esperava no mato de noite" } & & \end{array}$

Note que os dados acima, se comparados com os exemplos apresentados na seção 2.2, apontam para a possibilidade de verbos e nomes projetarem a mesma série de morfemas temporais, a saber: os sufixos de tempo passado $\{-k w e r\}$ e tempo futuro $\{-r a ̀ m\}$. A realização desses morfemas nos predicados verbais acima sustenta nossa análise de que esses morfemas não correspondem a morfemas derivacionais ${ }^{11}$, como ocorre nas línguas românicas. $\mathrm{Na}$

10 Estes exemplos, coletados por Duarte (2005), pertencem ao dialeto Tembé (a língua Tenetehára é composta por dois dialetos, a saber: o Tembé e o Guajajara). Recentemente, investigamos a possibilidade de esses morfemas de tempo "nominal" ocorrerem em verbos do dialeto Guajajára. No entanto, essa realização não se mostrou produtiva nessa variedade dialetal.

11 Há alguns contextos em que os morfemas $\{-k w e r\}$ e $\{-r a ̀ m\}$ ocorrem em DPs simples e a melhor tradução desses exemplos para o português é por meio dos morfemas derivacionais $\{$ ex- $\}$ e $\{q u a s e-\}$, conforme os exemplos a seguir:
(i) he=r-àpuz-ràm
(ii)
$h e=r-a ̀ p u z-k w e r$
1SG-1/2-casa-PAST
1SG-1/2-casa-FUT
"Minha quase-casa"
"Minha ex-casa"

No entanto, vale ressaltar que, apesar de a tradução fazer uso de morfemas derivacionais em português, esses morfemas em Tenetehára correspondem, na verdade, a marcas de tempo que podem ocorre com nomes e com verbos. 
verdade, esses morfemas são de fato de natureza flexional. Se os morfemas $\{-k w e r\}$ e $\{-r a ̀ m\}$ fossem de fato derivacionais, não esperaríamos que dados como (33) fossem possíveis em Tenetehára.

Vale ressaltar que a literatura acerca da interpretação temporal nas línguas naturais centrou-se principalmente na interpretação temporal dos predicados verbais. A principal razão disso pode ter sido pelo fato de as línguas europeias, normalmente estudadas por linguistas, terem uma riqueza de marcadores temporais sobre os verbos e não sobre os nomes. No entanto, como vimos acima, os sintagmas nominais também podem ser interpretados em termos de temporalidade. Assim, uma questão central que se coloca agora é o modo como essa temporalidade é codificada nos sintagmas nominais.

Como foi demonstrado, os morfemas de tempo nominal, de fato, contribuem, de alguma forma, com a localização do evento nominalizado no eixo temporal, assim como o evento descrito pelos predicados verbais é localizado. Mais precisamente, com base em Smith (1991), Kamp \& Reyle (1993) e Klein (1994), os marcadores temporais devem codificar uma relação entre o tempo da referência e o tempo da elocução (tempo da fala). Esta relação fica particularmente evidenciada por meio dos exemplos abaixo:

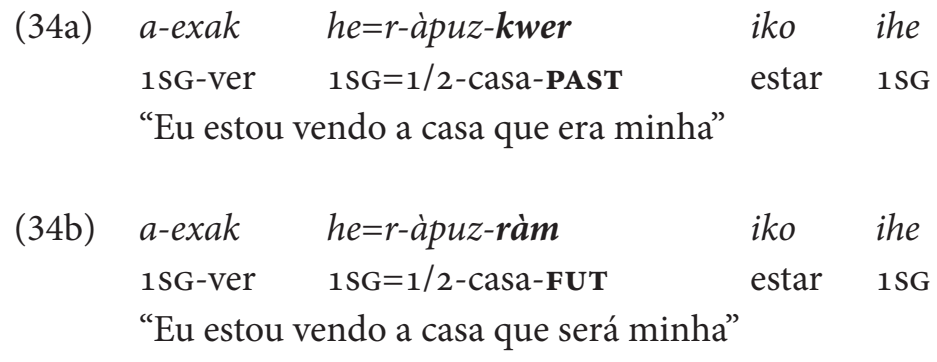

Veja que o morfema de tempo passado $\{-k w e r\}$ em (34a) relaciona o tempo do DP he=r-àpuz-kwer "a casa que era minha" com o tempo da elocução e não com o tempo da predicação verbal. Mais precisamente, o falante está vendo uma casa que ele ou ela possuía em um momento anterior ao tempo da fala. Paralelamente, note que, em (34b), o morfema de tempo futuro $\{-r a ̀ m\}$ relaciona o tempo do DP com o tempo da elocução. Observe que o 
que está em jogo nas sentenças acima é o tempo da posse da casa e não apenas o tempo do objeto possuído.

A mesma relação temporal pode ser explicitada por meios dos exemplos (31) e (32), em que o tempo marcado nos sintagmas nominais se comporta independente do tempo codificado na predicação verbal. Mais precisamente, os morfemas de tempo nominal relaciona o tempo do DP com o tempo da elocução, nos termos de Smith (1991), Kamp \& Reyle (1993) e Klein (1994). Vale ressaltar, no entanto, que há outros trabalhos, tais como Tonhauser (2002, 2006, 2007) e Matthewson (2005), que propõem que a projeção de DP jamais codificaria tempo (i.e. TP).

\subsubsection{Aspecto no DP e no CP}

Além de codificar tempo, a projeção de DP na língua Tenetehára instancia um núcleo funcional capaz de codificar aspecto gramatical, semelhantemente ao que ocorre nas predicações verbais. Compare os exemplos abaixo:

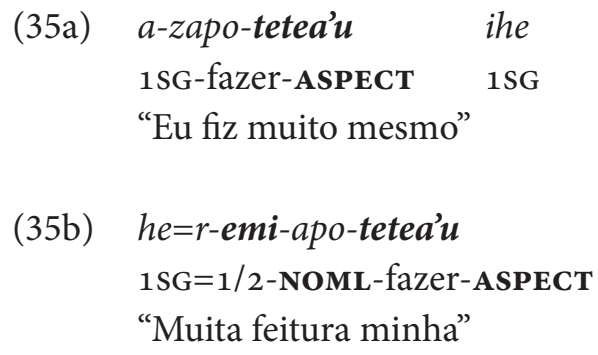

Veja que, no exemplo (35a), figura o verbo transitivo zapo "fazer". Nessa predicação verbal, realiza-se o elemento tetea'u, cuja função é a de inserir uma noção aspectual de intensidade. Em (35b), por sua vez, esse mesmo verbo é nominalizado pelo morfema $\{e m i-\}$, tornando a oração em um predicado nominalizado. Esse novo DP pode ainda receber o morfema de aspecto tetea'u, a fim de inserir a noção aspectual de intensidade. Observe ainda que a partícula tetea'u pode ainda coocorrer com o morfema de tempo futuro $\{-r a ̀ m\}$, conforme o exemplo (36a), ou com o morfema de tempo passado $\{-k w e r\}$, conforme (36b). 
(36a) he=r-emi-apo-tetea'u-ràm

$1 \mathrm{SG}=1 / 2$-NOML-fazer-ASPECT-FUT

"Muita feitura (futura) minha"

(36b) he=r-emi-apo-tetea'u-kwer

$1 \mathrm{SG}=1 / 2$-NOML-fazer-ASPECT-PAST

"Muita feitura (passada) minha"

A fim de demonstrar que o morfema aspectual tetea'u, em contexto de nominalização, pertence ao nível do DP e não ao nível do CP, veja o exemplo abaixo em que esse morfema ocorre depois do nominalizador $\{-p y r\}$ :

$$
\begin{array}{llll}
\text { u-kwaw-putar } & \text { i-apo-pyr-tetea'u-kwer } & \text { wà } & \text { nehe } \\
\text { 3-saber-FUT } & \text { 3-fazer-NOML-ASPECT-PAST } & \text { 3PL } & \text { FUT }
\end{array}
$$

"Eles vão saber o que muito foi feito"

(37b) w-exak kuzà i-ker-haw-tetea'u a'e 3-ver mulher 3-dormir-NOML-ASPECT 3SG

"A mulher viu muitos lugares para dormir"

Além do mais, o morfema de aspecto tetea’u pode ainda coocorrer com sintagmas nominais simples, conforme os exemplos abaixo:

(38a) màg-tetea'u i-’u re, o-ho kwarer w-àpuz ø-me a’e manga-INTS 3-comer depois 3-ir menino CORR-casa C-para 3SG

\begin{tabular}{|c|c|c|c|c|}
\hline$(38 b)$ & $\begin{array}{l}\text { ko } \\
\text { esta }\end{array}$ & $\begin{array}{l}\text { zapukaz } \\
\text { galinha }\end{array}$ & $\begin{array}{l}h \text {-eta } \\
3 \text {-ter }\end{array}$ & i-kawer-tetea'u \\
\hline
\end{tabular}
"Depois de comer muitas mangas, o menino foi para casa" 


\subsubsection{Voz causativa no DP e no CP}

De acordo com Castro (2007), Duarte \& Castro (2010), Silva (2010) e Camargos (2013), em termos descritivos, o morfema causativo $\{m u-\}$ em Tenetehára tem a função de transformar verbos inacusativos e inergativos em predicados transitivos, conforme o exemplo (39a) abaixo:
$h e=\emptyset-h y$
$u-\boldsymbol{m}(\boldsymbol{u})-u r$
u-kàm
$h e=\varnothing-w e$
a'e
1SG=1/2-mãe 3-CAUS-ir
CORR-peito
$1 \mathrm{SG}=\mathrm{C}-$ para
$3 S G$
"Minha mãe me deu o peito"

Veja que o verbo inacusativo ur "ir" recebe o morfema causativo $\{m u-\}$ no exemplo acima. A consequência desse processo é a formação do verbo transitivo causativo mur "dar" (lit.: "fazer ir"). Paralelamente, há, em (39b), a contraparte nominalizada do predicado em (39a). Veja que esse predicado nominalizado também possui em sua configuração interna o morfema causativo $\{m \mathcal{H}$ - .
(39b) i-katu-ahy $\left[_{\mathrm{DP}} h e=\varnothing-h y \quad h\right.$-emi-m(u)-ur-kwer ] he=ø-we a'e 3-bom-INTS 1SG=1/2-mãe 3-NOML-CAUS-ir-PAST 1SG=C-para 3SG "Foi muito bom o que foi dado pela minha mãe para mim" (i.e. o peito)

No entanto, se observamos atentamente a sentença (39b), veremos que o morfema causativo $\{m u$ - $\}$ não é a instanciação de um núcleo pertencente ao domínio de DP. Note que a raiz verbal ur "ir", antes de ser nominalizada pelo morfema $\{e m i$ - $\}$ e passar para o domínio do DP, recebe o causativo $\{m u-\}$. Mais precisamente, o morfema $\{e m i-\}$ nominaliza toda a predicação verbal $m(u)$-ur "dar".

\section{CASO E CONCORDÂNCIA}

Os dados apresentados até o presente momento, principalmente da língua Tenetehára, desafiam alguns modelos teóricos e trazem fortes implicações para outros. 
Primeiro, quanto às classes gramaticais, as categorias primitivas V (verbo) e N (nome), apresentadas no Quadro 1, apesar de possuírem propriedades bem definidas, conforme o Quadro 2, tais características são insuficientes para motivar uma distinção clara dessas duas categorias em Tenetehára. Isto fica particularmente evidenciado uma vez que os DPs na língua em análise apresentam características tradicionalmente atribuídas a orações verbais.

Segundo, em termos semânticos, os nomes não são vistos tradicionalmente como uma classe aberta à modificação temporal, uma vez que possuem inerentemente uma leitura temporal estática. Todavia, mostramos acima que a língua Tenetehára contradiz essa predição, quando apresenta morfemas de tempo nos DPs.

Terceiro, conforme a confrontação do Quadro 1 com o Quadro 2, o tempo, que é uma propriedade atribuída ao verbo, não deveria estar presente na sintaxe de sintagmas nominais, visto que os DPs são categorizados como $[-\mathrm{V}]$ e $[+\mathrm{N}]$. No entanto, já que os nomes são, de alguma forma, subespecificados para $[+\mathrm{V}]$ na língua em análise, há um problema para a proposta de subcategorização de Chomsky $(1965,1970)$.

Assim, com base no exposto acima, o objetivo da subseção seguinte é o de apresentar uma proposta teórica que explore o paralelismo entre o CP e o DP.

\subsection{Proposta de Duarte (2005)}

De acordo com Duarte (2005), a manifestação de tempo nos DPs em Tenetehára pode ser vista como o reflexo de que o DP recebe Caso nominativo ou Caso acusativo. Para isso, acompanhando Pesetsky \& Torrego (2001), há uma operação de concordância entre a categoria $\mathrm{D}^{\circ}$ e a categoria $\mathrm{T}^{\mathrm{b}} \mathrm{da}$ oração principal, a qual apaga os traços não interpretáveis em ambos os núcleos, a saber: (i) os traços-phi $[u \phi]$ em T $\mathrm{T}^{\mathrm{b}}$ e (ii) o traço tense $[u \mathrm{~T}]$ em $\mathrm{D}^{\circ}$.

A proposta de Duarte (2005) se fundamenta no seguinte fato: as instanciações de traços de tempo nos núcleos das projeções TP e DP podem servir como evidência a favor de que traços de tempo nominal podem ser vistos como reflexo da transmissão de Caso estrutural pelo núcleo $\mathrm{T}^{\mathrm{b}}$ ao núcleo $\mathrm{D}^{\circ}$. Tal hipótese se sustenta fundamentalmente na possibilidade de a sonda em $\mathrm{T}^{\mathrm{b}}$ checar os traços presentes no DP sujeito, conforme a configuração em (40). 


\section{Domínio do CP}

(40)

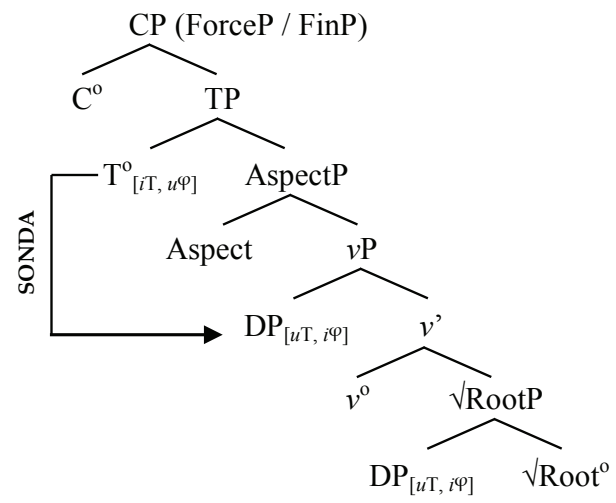

Observe que, na estrutura em (40), o núcleo de TP da predicação verbal, ao atribuir o Caso nominativo ao argumento externo projetado por $v \mathrm{P}$, estabelece uma operação de concordância entre a categoria $\mathrm{T}^{\mathrm{b}}$ e a categoria $\mathrm{D}^{\circ}$, a qual apaga os traços não interpretáveis nos dois núcleos.

Conforme Duarte (2005), o principal problema com essa hipótese, no entanto, é a possibilidade de os DPs na função sintática de objeto também poderem apresentar morfemas de tempo. Mais especificamente, em construções com dois argumentos nucleares, haveria dois DPs, um sujeito e um objeto, com traços de tempo não interpretável e apenas uma sonda em $\mathrm{T}^{\mathrm{O}}$ capaz de checá-los.

A fim de sanar esse conflito, Duarte (2005), fundamenta-se na proposta de Pesetsky \& Torrego (2002), segundo a qual a categoria funcional que entra em relação de concordância com o traço $[u \mathrm{~T}]$ do complemento de $\mathrm{V}$ (i.e. o complemento de $\sqrt{ } \operatorname{RootP}$ ) é uma instanciação de $\mathrm{T}^{\mathrm{b}}$, localizada em uma posição estrutural mais baixa que $\mathrm{T}^{\mathrm{b}}$ principal da sentença. Assim, há um núcleo $\mathrm{Ts}^{\circ}$, cuja função é atribuir o Caso nominativo, e um núcleo $\mathrm{To}^{\circ}$, cuja função é atribuir o Caso acusativo (= absolutivo). Dessa forma, haveria duas sondas com traços de tempo interpretável capazes de checar os traços no DP sujeito e no DP objeto ${ }^{12}$, conforme a estrutura configuracional abaixo, a qual foi adaptada de Duarte (2005:777):

${ }^{12}$ Uma solução alternativa seria adotar a proposta de Multiple Agree de Hiraiwa (2005), segundo a qual uma sonda P pode concordar com mais de um alvo G simultânea e derivacionalmente, como em (i): 


\section{Domínio do CP}

(41)

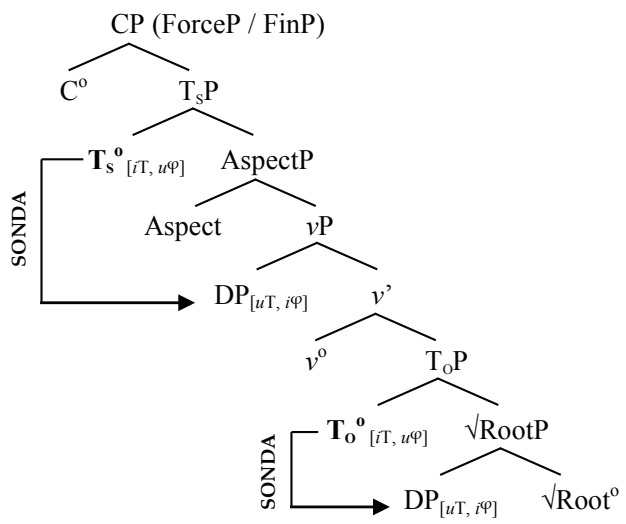

Nessa linha de investigação, Pesetsky \& Torrego (2002) propõem que os Casos nominativo e acusativo são a instanciação de um traço de tempo não interpretável $\left[u T\right.$ ] em $D^{\circ}$. Diante disso, os autores (2002:9) reformulam o Filtro de Caso proposto na Teoria de Regência e Ligação, da seguinte maneira:

\section{Filtro de Caso}

Um argumento deve carregar $\mathrm{T}[\mathrm{ut}]$ ou [it]

No entanto, a proposta segundo a qual a manifestação de tempo nos DPs é o reflexo de que essa projeção tem o traço de tempo não interpretável checado pelo núcleo $\mathrm{T}^{\mathrm{b}}$ da oração principal apresenta um problema empírico e uma implicação teórica. Como vimos na seção anterior, não há uma relação biunívoca entre o tempo no DP e o tempo na oração. Veja que, em (43), os DPs recebem o morfema de tempo passado $\{-k w e r\}$, enquanto a oração está no tempo futuro, como indica as partículas putar e nehe.

(43) w-exak-putar he=r-emi-reko-kwer he-r-emi-apo-kwer a'e nehe 3SG-ver-FUT $\quad 1 \mathrm{SG}=1 / 2$-NOML-estar-PAST $1 \mathrm{SG}=1 / 2$-NOML-fazer-PAST 3SG FUT "Minha antiga esposa deseja ver aquilo que foi feito por mim"

(i)

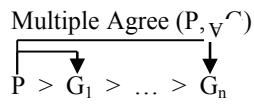


Note que a assimetria entre o tempo do DP, tanto do sujeito quanto do objeto, e o tempo do CP demonstra que esses dois sintagmas nominais projetam tempo de forma independente de $\mathrm{T}^{\mathrm{b}}$ da oração principal. Assim, não há motivação empírica para propor a checagem de traços, uma vez que não há uma concordância entre o tempo do $\mathrm{CP}$ com o tempo do DP: não há compatibilidade, operação de AGREE, entre a sonda e o alvo, ferindo a proposta de checagem de traços de Chomsky $(2000,2001)$. Mais precisamente, não existe identidade entre os traços da sonda e o alvo. Se estivermos certos, dados como (43) configuram como contraexemplos para a proposta de Pesetsky \& Torrego $(2001,2002)$.

Por fim, a hipótese acima ainda contém fortes implicações para o Modelo de Fases de Chomsky (2000, 2001). Note que a proposta de Duarte (2005) se fundamenta na possibilidade de uma sonda em $\mathrm{T}^{\mathrm{b}}$ checar traços internos ao DP, embora Adger (2003) proponha que a projeção DP, assim como CP e $v$, constitua-se em uma fase forte. Logo, se a proposta de Adger (2003) estiver correta, os traços de tempo no DP não são provavelmente acessíveis para posteriores derivações, inclusive uma possível checagem de traço por $\mathrm{T}^{\mathrm{b}}$ da oração principal.

Diante disso, proporemos, na próxima seção, que o traço não interpretável de tempo dentro do DP, se houver, deve ser checado dentro da própria projeção máxima DP, antes que seja enviada para spell-out. Mais detalhadamente, aventaremos a hipótese de se interpretar a realização morfológica de tempo nos DPs como sendo o reflexo do mecanismo sintático que checa o Caso abstrato nos argumentos possuidores.

\subsection{Nossa proposta}

Nossa análise parte da proposta de Szabolcsi $(1983,1994)$ e Lefebvre \& Muysken (1988), segundo a qual, em termos de Caso e concordância, algumas línguas usam a mesma marcação de Caso para DP agente e DP possuidor, conforme os exemplos abaixo, repetidos de (3) e (4):

$\begin{array}{llll}\text { te } & v e-t t-e l & \text { egy } & \text { kalap-ot } \\ \text { 2sG.NOM comprar-PAST-2SG.ID } & \text { ID } & \text { chapéu-ACC } \\ \text { "Você comprou um chapéu" } & & \end{array}$




$\begin{array}{lll}a & \text { te } & k a l a p-j a-i-d \\ \text { D } & \text { 2sG.NOM } & \text { chapéu-POss-PL-2sG }\end{array}$

"Seus chapéus"

$\begin{array}{lll}\text { angute- } \boldsymbol{m} & \text { nera-a } & \text { neqa } \\ \text { homem-RELAT } & \text { comer-3sG.3sG } & \text { peixe } \\ \text { "O homem está comendo o peixe" } & \end{array}$
angute- $m$
qimugta-i
homem-RELAT
cachorro-3PL.ABS.3sG.ERG
"Os cachorros do homem"

Veja que o húngaro usa a marca de nominativo $\{t e\}$, como em (44), e o yup'ik esquimó utiliza a marca de ergativo $\{-m\}$ (também chamado de Caso relativo), como em (45), a fim de assinalar os argumentos agentes e possuidores. Em Tenetehára, no entanto, há a mesma marcação $0^{13}$ de Caso para DPs objetos de transitivos e DPs possuidores. Para sustentar nossa proposta, considere o exemplo abaixo em que o predicado aciona no verbo a série de morfemas relacionais, a qual indica o licenciamento do Caso absolutivo (= acusativo).

$$
\begin{aligned}
& \text { [he=r-exak kuzà [ u-memyr i-petek mehe] a'e ] } \\
& \text { 1SG=1/2-ver mulher CORR-filho 3-bater quando } 3 \mathrm{SG} \\
& \text { "A mulher }{ }_{j} \text { me viu quando (eu) batia em seu filho" }
\end{aligned}
$$

Mais precisamente, o verbo exak "ver" da oração principal recebe o prefixo relacional $\{r$ - $\}$ a fim de assinalar a adjacência do objeto de primeira pessoa he "eu". O verbo petek "bater", por seu turno, aciona o prefixo relacional $\{i$ - $\}$

${ }^{13}$ Diferentemente do yup'ik esquimó e do quéchua de Cuzco, os DPs em Tenetehára não recebem morfemas de Caso. Conforme Duarte (1997, 2003, 2005, 2007, 2012), o sistema de Caso nessa língua emerge devido às duas séries de prefixos de concordância, a saber: (i) os marcadores pessoais $\{a-\},\{$ ere- $\},\{u-\infty w-\infty o-\},\{$ uru- $\},\{$ za- $\infty$ xi- $\}$ e $\{$ pe- $\}$, os quais assinalam o Caso nominativo ao seu sujeito; e (ii) os prefixos relacionais $\{\mathrm{i}-\infty \mathrm{h}-\}$ e $\{\varnothing-\infty \mathrm{r}-\}$, que assinalam o Caso absolutivo (= acusativo) ao objeto de verbos transitivos e sujeito de verbos descritivos. 
para codificar o objeto umemyr "o seu filho". Como pode ser notado, esses mesmos morfemas de concordância ocorrem no núcleo de DPs a fim de codificar o argumento possuidor, conforme os exemplos abaixo:

$$
\begin{aligned}
& \text { he=r-emi-(e)r(u)-eko } \\
& \text { 1SG=1/2-NOML-APPL-estar } \\
& \text { "minha esposa" }
\end{aligned}
$$

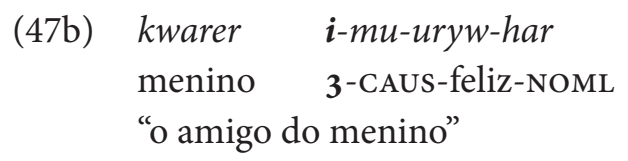

Veja que, em (47), há o acionamento da série de prefixos relacionais a fim de estabelecer a atribuição de Caso estrutural abstrato ao possuidor. Com base nesses exemplos, vemos que essa língua emprega a mesma série de prefixos de concordância para se referir a possuidores e a objetos de transitivos.

Acompanhando o essencial da proposta de Hiraiwa (2005), defendemos a ideia de que a manifestação de tempo nos DPs pode ser vista como reflexo de que há o licenciamento de Caso dentro da projeção de DP. Mais precisamente, o Caso é licenciado ao argumento possuidor. Veja que tal fenômeno é paralelo à atribuição de Caso absolutivo (= acusativo) ao argumento interno da predicação verbal.

Veja que o principal fato empírico a favor dessa hipótese advém da possibilidade de o possuidor e o objeto de transitivo acionar no núcleo de DP e $\mathrm{CP}$, respectivamente, a mesma série de prefixos relacionais $\{i-\infty h-\}$ e $\{\varnothing-\infty$ $r$-\}. Isto é naturalmente esperado, uma vez que assumimos que as projeções CP e DP, pelo menos em Tenetehára, são análogas.

Assim, com base no paralelismo entre CP e DP e no modelo de checagem de traços, conforme Chomsky (2000, 2001), uma alternativa é assumirmos que a realização de tempo nos DPs é o reflexo da transmissão de Caso estrutural aos argumentos possuidores. Assim, há uma operação de AGREE entre o argumento possuidor e a projeção $\mathrm{T}^{\mathrm{b}}$ interna ao DP, conforme a estrutura abaixo: 


\section{Domínio do DP}

(48)

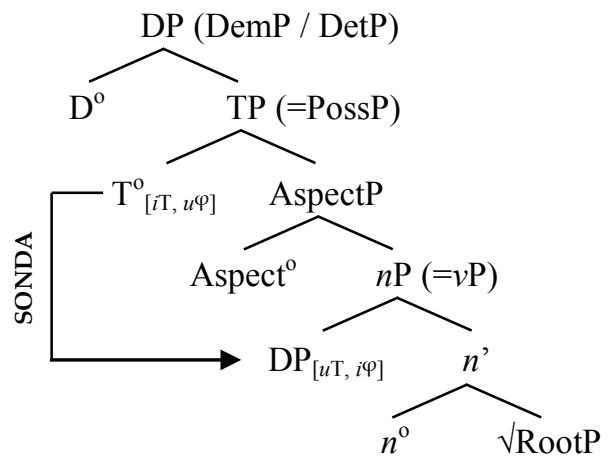

Veja que a estrutura em (48) não corresponde a um CP, mas sim a um DP que projeta tempo, como se pode notar pela projetação de TP (= PossP), o qual é complemento do núcleo de DP. Observe que a operação de concordância que se estabelece entre o argumento possuidor e a projeção $\mathrm{T}^{\mathrm{b}}$ interna ao DP apaga os traços não interpretáveis em ambos os núcleos, a saber: (i) os traços-phi $[u \phi]$ em $\mathrm{T}^{\mathrm{b}}$ e o traço de tempo $[u \mathrm{~T}]$ no possuidor. Além do mais, a assunção de que a projeção PossP corresponde à projeção TP pode ser empiricamente motivada, conforme os exemplos abaixo:
tuwihaw
h-àpuz-kwer
ø-pupe
$w$-ixe
$w a ̀$
chefe
3-casa-PAST
C-dentro 3-entrar
PL
"Eles entraram na casa que era do chefe"

$\begin{array}{lllll}\text { tuwihaw } & \boldsymbol{h} \text {-àpuz-ràm } & \varnothing \text {-pupe } & \text { w-ixe } & \text { wà } \\ \text { chefe } & \text { 3-casa-FuT } & \text { C-dentro } & \text { 3-entrar } & \text { PL }\end{array}$

"Eles entraram na casa que será do chefe"

Veja que, nos exemplos acima, os morfemas de tempo $\{-r a ̀ m\}$ e $\{-k w e r\}$, quando ocorrem no núcleo de sintagma possessivo, têm a função de conectar a relação de posse no eixo temporal. Mais precisamente, a morfologia temporal modifica o tempo da posse. Desse modo, é possível notar a estreita relação entre o tempo nominal e a posse. Portanto, a fim de justificar a 
estrutura configuracional em (48), defendemos que o DP objeto da oração em (50a) tenha a derivação proposta em (50b):

(50a) a-exak-putar [ kàpitàw h-emi-mu-apyk-tetea'u-kwer ] ihe nehe 1SG-ver-FUT cacique 3-NOML-CAUS-sentar-ASPECT-PAST 1SG FUT "Eu verei aquilo que muito foi escrito pelo cacique (que é do cacique)"

\section{Domínio do DP}

(50b)

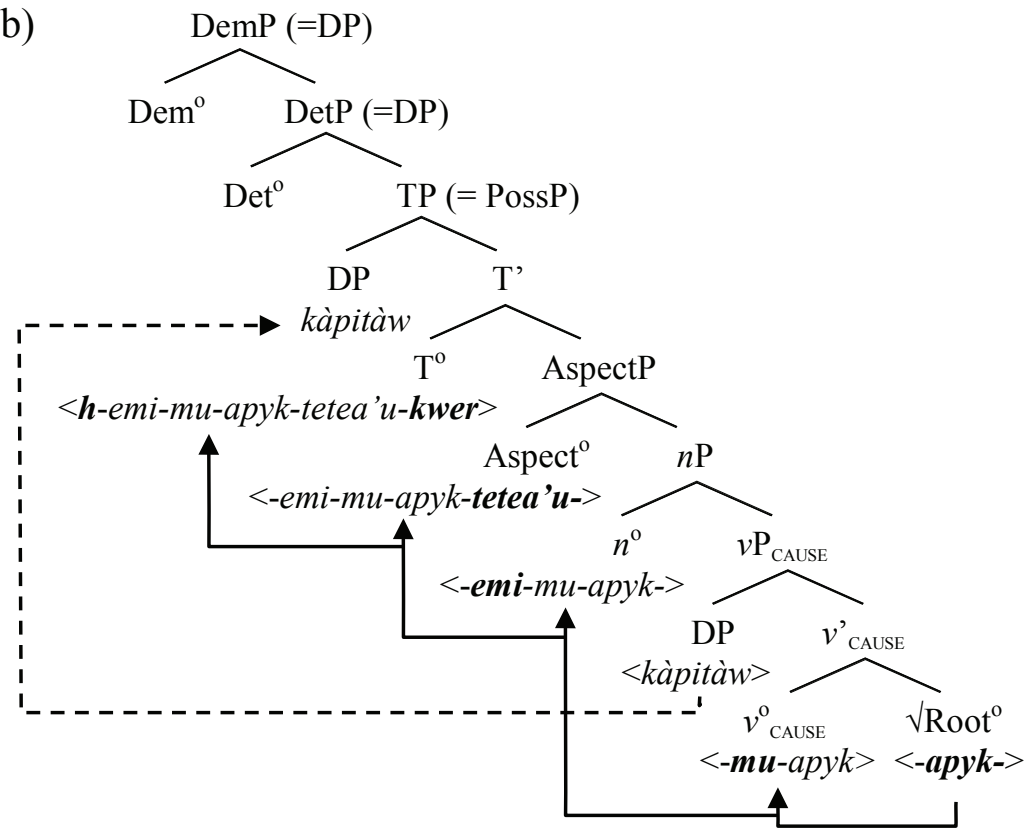

Note que, na estrutura acima, a raiz apyk "sentar" se incorpora, inicialmente ao núcleo causativo $v_{\text {CAuse, }}^{\text {o }}$ o qual e morfologicamente preenchido pelo morfema $\{m u$ - $\}$. Ademais, um argumento externo, o DP kàpitàw "o cacique", é introduzido na estrutura argumental da predicação verbal. Vale ressaltar que o núcleo de $v \mathrm{P}_{\text {CAusE }}$ ainda verbaliza a raiz apyk "sentar". Posteriormente, o verbo muapyk "escrever (lit. fazer sentar)" se move para o núcleo de $n \mathrm{P}$, o qual é instanciado pelo morfema nominalizador \{emi-\}, 
morfema que nominaliza predicados verbais. Depois disso, o conteúdo no núcleo de $n^{\circ}$ se move para o núcleo de AspectP, a fim de codificar o aspecto nominal intensivo tetea'u. Por fim, o núcleo Aspect ${ }^{\circ}$ se desloca para o núcleo de PossP afim de codificar o tempo nominal passado $\{-k w e r\}$. Esta projeção, por sua vez, projeta a posição de especificador, a qual receberá o DP kàpitàw “o cacique”. Este argumento, nesta posição, receberá a interpretação semântica de possuidor.

Veja que uma operação de concordância ocorre entre o argumento possuidor kàpitàw "cacique" e a projeção T ${ }^{\mathrm{b}}\left(\mathrm{i} . e\right.$. Poss $^{\circ}$ ) interna ao DP, a qual apaga os traços não interpretáveis em ambos os núcleos, a saber: (i) os traços-phi $[u \phi]$ em $\mathrm{T}^{\mathrm{b}}$ e o traço de tempo $[u \mathrm{~T}]$ no possuidor. Mais precisamente, observe que o prefixo relacional $\{h-\}$ acionado no núcleo do sintagma possessivo concorda em pessoa com o argumento possuidor.

Observe ainda que a análise acima não infringe o Modelo de Fase conforme foi delineado por Chomsky $(2000,2001)$ e Adger (2003): o traço não interpretável de tempo interno ao sintagma determinante é checado dentro da própria projeção máxima $\mathrm{DP}$, antes que seja enviada para $\mathrm{PF}$ (Phonetic Form).

\section{CONSIDERAÇÕES FINAIS}

Neste trabalho, assumimos que os DPs em Tenetehára, ao lado dos CPs, projetam núcleos funcionais capazes de codificar categorias de tempo $\{-k w e r\}$ e $\{-r a ̀ m\}$ e de aspecto $\{$ tetea'u\}. Para tanto, apoiamo-nos em processos de nominalizações por meio dos morfemas $\{-h a w\},\{-m a j e\},\{-h a r\}$, $\{e m i-\}$ e $\{-p y r\}$.

Com base na simetria entre CPs e DPs e na proposta de Chomsky (2000, 2001), sustentamos a hipótese de que os sufixos temporais nos DPs são o reflexo da atribuição de Caso estrutural ao argumento possuidor, paralelamente à atribuição de Caso estrutural ao objeto da predicação transitiva. A principal evidência desse paralelismo é o acionamento do paradigma absolutivo (i.e. prefixos relacionais) em construções transitivas e nominais. Assim, nossa proposta é a de que predicados nominais e predicados verbais 
não se diferem, quanto a suas projeções lexicais e funcionais, uma vez que há certo paralelismo entre as duas estruturas.

A fim de responder a pergunta inicial (a saber: qual é a origem da simetria entre o $\mathrm{CP}$ e o DP?) assumimos, como alternativa, seguindo Hiraiwa (2005), que as projeções superficiais de CP e DP seriam a instanciação de uma estrutura subjacente comum, conforme o paralelismo entre as estrutura abaixo, repetido de (1) e (2). O principal argumento a favor dessa hipótese seria as propriedades comuns às duas estruturas, tais como: tempo, aspecto e sistema de concordância. Nossa proposta, nesse sentido, contradiz Chomsky $(1965,1970)$ e trabalhos que separam as projeções CP e DP em dois conjuntos distintos.

\section{Domínio de CP}

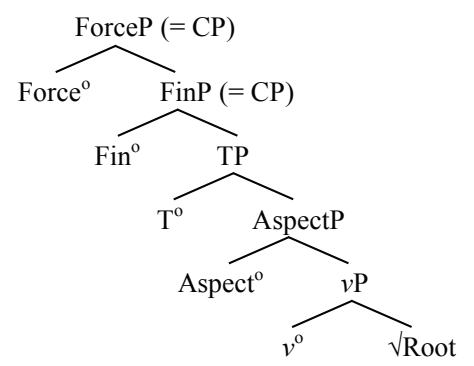

\section{Domínio de DP}

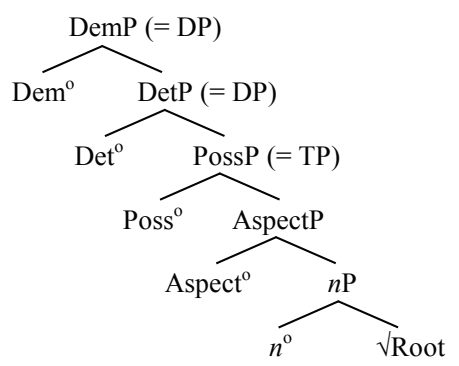

\section{REFERÊNCIAS BIBLIOGRÁFICAS}

ABNEY, Steven Paul. The English Noun Phrase in its Sentential Aspect. Tese (Doutorado). Cambridge: The MIT Working Papers in Linguistics, 1987.

$\mathrm{ABOH}$, Enoch Oladé. The morphosyntax of complement-head sequences: clause structure and word order patterns in Kwa. New York: Oxford University Press, 2004. 
ADGER, David. Core syntax. Oxford: Oxford University Press, 2003

ALEXIADOU, Artemis. Tense (and Mood) in the nominal domain. In: WORKSHOP ON THE LINGUISTIC REPRESENTATION OF TENSE AND MOOD, 2005, Stuttgart. Papers... Stuttgart: University of Stuttgart, 2005.

BELLETTI, Adriana. Structures and beyond: the cartography of syntactic structures. New York: Oxford University Press, 2004.

BENDOR-SAMUEL, David. Hirachical structures in Guajajára. Norman: Summer Institute of Linguistics, 1972.

BOUDIN, Max H. Dicionário de Tupi Moderno: dialeto tembé-ténêtéhar do alto rio Gurupi. São Paulo: Conselho Estadual de Artes e Ciências Humana, 1978.

BURTON, Strang C. Past tense on nouns as death, destruction and loss. The proceedings of NELS, v. 27, p. 65-78, 1997.

CAMARGOS, Quesler Fagundes. Estruturas Causativas em Tenetehára: uma abordagem minimalista. Dissertação (Mestrado). Universidade Federal de Minas Gerais, Belo Horizonte, 2013.

CAMARGOS, Quesler Fagundes; DUARTE, Fábio Bonfim. ¿Hácia dónde fueron los adjetivos en tenetehára?. In: GARAY, Ana Fernández; CENSABELLA, Marisa; MALVESTITTI, Marisa. Lingüística amerindia: contribuiciones y perspectivas. Buenos Aires: Editorial de la Facultad de Filosofia y Letras Universidad de Buenos Aires, 2013.

CARVALHO, Márcia Goretti Pereira. Sinais de Morte ou Vitalidade?. Mudanças Estruturais na Língua Tembé: contribuição ao estudo dos efeitos de contato linguístico na Amazônia Oriental. Dissertação (Mestrado).Universidade Federal do Pará, Belém, 2001. 
CASTRO, Ricardo Campos. Interface morfologia e sintaxe em Tenetehára. Dissertação (Mestrado), Universidade Federal de Minas Gerais. Belo Horizonte, 2007.

CHOMSKY, Noam. Aspects of the Theory of Syntax. Cambridge: The MIT Press, 1965.

. Remarks on nominalization. In: JACOBS, Roderick; ROSENBAUM, Peter (Ed.). Readings in English transformational grammar. Waltham: Ginn, 1970.

. On Binding. Linguistic Inquiry. v. 11, p. 1-46, 1980.

. Knowledge of Language: its nature, origin and use. New York: Praeger, 1986.

. The minimalist program. Cambridge: The MIT Press, 1995.

. Minimalist inquiries. In: MARTIN, Roger. Step by step: essays on minimalism in honor of Howard Lasnik. Cambridge: The MIT Press, 2000.

. Derivation by phase. In: KENSTOWICZ, Michael; HALE, Ken. A life in language. Cambridge: The MIT Press, 2001.

CINQUE, Guglielmo. Adverbs and functional heads: across-linguistic perspective. New York: Oxford University Press, 1999.

CINQUE, Guglielmo. Functional structure in DP and IP: the cartography of syntactic structures. New York: Oxford University Press, 2002.

COLLINS, Chris. Aspects of plurality in $\bigotimes$ Hoan. In: Language, v. 77, p. 456476, 2001. 
DUARTE, Fábio Bonfim. Análise gramatical das orações da Língua Tembé. Dissertação (Mestrado), Universidade de Brasília. Brasília 1997.

DUARTE, Fábio Bonfim. Ordem dos constituintes e movimento em Tembé: minimalismo e anti-simetria. Tese (Doutorado), Universidade Federal de Minas Gerais. Belo Horizonte, 2003.

DUARTE, Fábio Bonfim. Manifestação de traços de tempo em D/NPS na língua Tenetehára. In: Revista de Estudos Linguísticos do GEL, Campinas, v. 35, p. 773-881, 2005.

DUARTE, Fábio Bonfim. Estudos de morfossintaxe Tenetehára. Belo Horizonte: Faculdade de Letras da UFMG, 2007.

DUARTE, Fábio Bonfim. Tenetehára: A predicate-fronting language. In: The Canadian Journal of Linguistics / La revue canadienne de linguistique, v. 57, p. 359-386, 2012.

DUARTE, Fábio Bonfim; CASTRO, Ricardo Campos. Inergatividade, Estrutura Casuativa e Incorporação Nominal em Tenetehára. In: CABRAL, Ana Suelly Arruda Câmara; RODRIGUES, Aryon Dall'Igna; DUARTE, Fábio Bonfim (Org.). Línguas e Culturas Tupí. Campinas: Curt Nimuendajú, 2010. v. 2. p. 43-62.

GALOWAY, Brent. A grammar of Upriver Halkomelem. Tese (Doutorado), University of California. Berkeley, 1993.

HARRISON, Carl. Verb prominence, verb initialness, ergativity and typological disharmony in Guajajara. In: DERBYSHIRE, Desmond C.; PULLUM, Geoffrey K. (Ed.). Handbook of Amazonian Languages. Berlin: Mouton de Gruyter, 1986.

HIRAIWA, Ken. Dimensions of symmetry in syntax: agreement and clausal architecture. Tese (Doutorado). Cambridge: The MIT Press, 2005. 
KAMP, Hans; REYLE, Uwe. From discourse to logic. Dordrecht: Kluwer, 1993.

KLEIN, Wolfgang. Time in language. New York: Routledge, 1994.

LARSON, Richard. On the double object construction. In: Linguistic Inqui$r y$, v. 19, p. 335-391, 1988.

LECARME, Jacqueline. Tense in the nominal system: the Somali DP. In: LECARME, Jacqueline; LOWENSTAMM, Jean; SHLONSKY, Ur. Studies in Afroasiatic Grammar. In: SECOND CONFERENCE ON AFROASIATIC LANGUAGES. Papers from the Sophia Antipolis, 16 June, 1994. The Haque: Holland Academic Graphics, 1996.

LEFEBVRE, Claire; MUYSKEN, Pieter. Mixed categories: nominalization in Quechua. Dordrecht: Kluwer Academic Publishers, 1988.

LOPES, Mário Alexandre Garcia. Aspectos gramaticais da língua Kảapor. Tese (Doutorado), Universidade Federal de Minas Gerais. Belo Horizonte, 2009.

MARANTZ, Alec. No escape from syntax: don't try morphological analysis in the privacy of your own lexicon. In: Penn Working Papers in Linguistics, v. 4, n. 2, p. 201-225, 1997.

MATTHEWSON, Lisa. On the absence of tense on determiners. In: Lingua, v. 115, p. 1697-1735, 2005.

PESETSKY, David; TORREGO, Esther. T-to-C movement: causes and consequences. In: KENSTOWICZ, Michael. Ken Hale: a life in Language. Massachussets: The MIT Press, 2001.

PESETSKY, David; TORREGO, Esther. Tense, Case and the nature of Syntactic Categories. In: GUÉRON, Jacqueline; LECARME, Jacqueline. The Syntax of Time. Cambridge: The MIT Press, 2002. 
POLLOCK, Jean-Yevs. Verb movement, universal grammar and the structure of IP. In: Linguistic Inquiry, v. 20, p. 365-424, 1989.

PYLKKÄNEN, Liina. Introducing Arguments. Tese (Doutorado), Cambridge: The Massachusetts Institute of Technology, 2002.

RIZZI, Luigi. The fine structure of the left periphery. In: HAEGEMAN, Liliane (Ed). Elements of grammar: handbook in generative syntax. Dordrecht: Kluwer Academic Publishers, 1997.

RIZZI, Luigi. The structure of CP and IP: the cartography of syntactic structures. New York: Oxford University Press, 2004.

RODRIGUES, Aryon Dall'Igna. Morfologia do Verbo Tupi. In: Revista Letras, Curitiba, v. 1, p. 121-152, 1953.

RODRIGUES, Aryon Dall'Igna. Relações internas na família linguística Tupí-Guaraní. In: Revista de Antropologia, v. 27/28, p. 33-53, 1985.

RODRIGUES, Aryon Dall'Igna. I and You = neither I nor You: the Personal System of Tupinamba. In: PAYNE, Doris L. Amazonian Linguistics: Studies in Lowland South American Languages. Austin: University of Texas Press, 1990. p. 393-406.

SEKI, Lucy. Gramática do Kamaiurá: Língua Tupi-Guarani do Alto Xingu. Campinas: Editora da Unicamp, 2000.

SILVA, Tabita Fernandes. História da língua Tenetehára: contribuições aos estudos histórico-comparativos sobre a diversificação da família Tupí-Guaraní do tronco Tupí. Tese (Doutorado), Universidade de Brasília. Brasília, 2010.

SMITH, Carlota. The parameter of aspect. Dordrecht: Kluwer, 1991. 
SZABOLCSI, Anna. The possessor that ran away from home. In: The Linguistic Review, v. 3, p. 89-102, 1983.

SZABOLCSI, Anna. The noun phrase. In: KIEFER, Ferenc; KISS, Katalin É. Syntax and semantics 27: the syntax of Hangarian. San Diego: Academic Press, 1994.

TONHAUSER, Judith. A dynamic semantic account of the temporal interpretation of noun phrases. In: JACKSON, Brendan. Semantics and Linguistic Theory. Ithaca: CLC Publications, 2002. p. 286-305.

TONHAUSER, Judith. The temporal semantics of noun phrases: Evidence from Guaraní. Tese (Doutorado), Stanford University. Stanford, 2006

TONHAUSER, Judith. Nominal Tense?. The Meaning of Guaraní Nominal Temporal Markers. In: Language, v. 83, n. 4, p. 831-869, dez. 2007

VANGSNES, Øystein. The identification of functional architecture. Tese (Doutorado). University of Bergen, Bergen, 1999.

WILTSCHKO, Martina. On the interpretability of tense on D and its consequences for case theory. In: Lingua, v. 113, p. 659-696, 2003.

ZAMPARALLI, Roberto. Layers in the determiner phrase. New York: Garland, 2000. 